\title{
Hidatik Akut Pankreatit
}

\section{Hydatid Acute Pancreatitis}

\section{Özlem Özer Çakır, Hüseyin Ataseven, Ali Demir}

Selçuk Üniversitesi Meram Tıp Fakültesi, İç Hastalıkları Anabilim Dalı, Gastroenteroloji Bilim Dalı, Konya Türkiye

\section{ÖZET}

Karaciğer hidatik kistlerinin safra ağacı içine rüptürü bilinmektedir, fakat akut pankreatit nadir bir komplikasyonudur. İntrabiliyer rüptür ilk kez Dew tarafından 1928'de bildirilmiştir. Intrabiliyer rüptür hepatik hidatik kistin ciddi bir komplikasyonudur. Erişkin hastalarda insidans \%1-25 arasındadır. Bizim olgumuzda hepatik kist materyalinin ana safra kanalına göç edebileceğini ve papiller orifise impakte olup akut pankreatiti provake edebileceğini göstermeyi amaçladık. Akut pankreatitle gelen hastada ayrıcı tanıda biliyer nedenler arasında parazitik enfeksiyonların da düşünülmesi gerekmektedir. (Turkiye Parazitol Derg 2012; 36: 251-3)

Anahtar Sözcükler: Hidatik kist, akut pankreatit, intrabiliyer rüptür Geliş Tarihi: 28.02.2012

Kabul Tarihi: 29.09.2012

\section{ABSTRACT}

Liver hydatid cysts are known to rupture into the biliary tree, but acute pancreatitis is a rare complication of intra-biliary rupture. Intra-biliary rupture was first reported in 1928 by Dew. Intra-biliary rupture is a serious complication of hepatic hydatid cysts. The incidence varies from $1 \%$ to $25 \%$ in adult patients. In our case, we aimed to show the migration of the material of a hepatic hydatid cyst to the common bile duct and the impaction of hydatid membrane in the papillary orifice, which may cause acute pancreatitis. Parasitic infections should be considered as a differential diagnosis in patients with acute biliary pancreatitis. (Turkiye Parazitol Derg 2012; 36: 251-3)

Key Words: Hydatid cyst, acute pancreatitis, intra-biliary rupture

Received: 28.02.2012

Accepted: 29.09.2012

\section{GiRiş}

Kistik ekinokokkozis (KE), Echinococcus granulosus'un neden olduğu zoonotik bir hastalıktır. Bu hastalık Akdeniz, Asya, Uzak Doğu ve Latin Amerika'da birçok ülkede endemiktir. Hidatik kistlerin \%75'i karaciğerde bulunur. Hastalar yıllarca asemptomatik olabilirler ve genellikle nonspesifik şikayetlere sahiptirler. Fakat herhangi bir zamanda ortaya çıkan bazı komplikasyonlar erken tedavi edilmezse hayatı tehdit edebilirler (1).

Karaciğer, hidatik kistlerin en sık yerleştiği yerdir, daha az sıklıkla akciğerler, nadiren de dalak, böbrekler, beyin, kaslar, kemik ve pankreasta bulunabilir. Kistin biliyer kanala rüptürü nadirdir ve obstruktif sarılık ya da kolanjit ile kendini gösterebilir (2, 3). Biliyer kanalda hidatik membranların görüldüğü birkaç olgu bildirilmiştir $(4,5)$. Karaciğer kistlerinin safra ağacı içine rüptürü bilinmektedir, fakat akut pankreatit nadir bir komplikasyonudur. Intrabiliyer rüptür ilk kez Dew tarafından 1928'de bildirilmiştir (6). Intrabiliyer rüptür hepatik hidatik kistlerin ciddi bir komplikasyonudur. Erişkin hastalarda insidansı \%1-25 arasındadır (7).

Bizim olgumuzda hepatik kist hidatik materyalinin ana safra kanalına göç edebileceğini, papiller orifise impakte olup,

\section{Bu olgu 27. Ulusal Gastroenteroloji Haftası 2010'da poster olarak sunulmuştur.}

Yazışma Adresi / Address for Correspondence: Dr. Özlem Özer Çakır, Selçuk Üniversitesi Meram Tıp Fakültesi, Iç̧ Hastalıkları Anabilim Dalı, Gastroenteroloji Bilim Dalı, Konya Türkiye Tel: +90 2163322236587 E-posta: tansozlem@yahoo.com 
bunun da akut pankreatiti provoke edebileceğini göstermeyi amaçladık. Akut pankreatitle gelen hastada ayrıcı tanıda biliyer nedenler arasında parazitik enfeksiyonların da düşünülmesi gerekmektedir.

\section{OLGU SUNUMU}

Altı gün önce ishalle başlayan karın ağrısı, bulantı ve kusma yakınması olan 60 yaşında erkek hasta, karın ağrısının giderek artması ve sağ üst kadrandan başlayıp göbek çevresine yayılması üzerine acil servise başvurmuştur. Hastanın özgeçmişinde; iki yıldır Tip 2 diyabetes mellitus hastası olduğu ve metformin 1000 mg 2x1 kullandığı öğrenildi. Hastada safra taşı, alkol kullanımı, geçirilmiş operasyon öyküsü yoktu.

Fizik muayenede; kan basıncı 110/70 mmHg, nabız 72/dk, ateş $37^{\circ} \mathrm{C}$ idi. Batın muayenesinde sağ üst kadranda hassasiyet mevcuttu, defans ve rebound yoktu. Laboratuar incelemesinde; Hgb: $12.6 \mathrm{~g} / \mathrm{dL}$, Htc: \%37.9, Plt: 264 000/mm³, Sedimantasyon: 109 mm/h idi. AST: $88 \mathrm{U} / \mathrm{L}, \mathrm{ALT}: 156 \mathrm{U} / \mathrm{L}, \mathrm{GGT}: 921 \mathrm{U} / \mathrm{L}, \mathrm{ALP}: 379 \mathrm{U} / \mathrm{L}$, t.bil: 6.9 mg/dL, d.bil: 4.16 mg/dL idi. Amilaz: 655 u/L, Lipaz: 1113 u/L idi. Hastanın serum elektrolitleri normaldi. Üst batın USG de; karaciğer konum ve konturu tabii idi. Parankim ekosu yağlanmaya sekonder artmıştı. Kaudot lob düzeyinde yaklaşık $36 \times 50$ mm çapta periferi kalsifiye içerisinde kistik alanlar ve hiperekoik görünümler olan hidatik kist lehine lezyon izlendi. İntrahepatik safra yollarında hava imajları vardı. Safra kesesi duvarı belirgin olup lümende belirgin posterior gölgelenmesi olmayan ekojeniteler (kolesterol kristalleri) izlendi.

Biliyer pankreatit düşünülen hastaya Endoskopik Retrograd Kolanjio Pankreatografi (ERCP) planlandı. ERCP'de; Ampulla waterii'ye oturmuş beyaz renkli hidatik kist membranı izlendi. Bu membran snare ile çıkarıldı. Koledok kanülize edildi. Opak madde verildiğinde koledoğun hafif dilate olduğu görüldü. Endoskopik sfinkterotomi yapıldı, koledok balonla sıvazlanarak işleme son verildi (Resim 1).

ERCP sonrası karın ağrısı olmayan hastanın amilaz, lipaz değerleri düştü, kolestatik enzimleri ve bilirubinleri geriledi. ERCP sırasında çıkarılan materyal patolojiye gönderildi. Histopatolojide hidatik kist membranı ve protoskoleksler izlendi (Resim 2). indirekt hemaglutinasyon (IHA) ile yapılan analizde anti-Echinococcus granulosus antikorları $1 / 640$ dilusyonda pozitif idi. Albendazol 200 mg 2x2 başlanan ve genel durumu ile şikayetleri gerileyen hastaya medikal tedavi sonrası karaciğer KE cerrahi tedavi planlandı.

\section{TARTIŞMA}

Biliyer ağacın parazitik enfeksiyonları tropikal ve subtropikal ülkelerde yüksek prevelans ve insidansa sahiptir. Biliyer ağaca rüptür karaciğer KE'nin bilinen bir komplikasyonudur. Bu komplikasyon neticesinde kist kavitesinde enfeksiyona ve biliyer ağaçla ilişkili sekonder problemlere yol açar. Biliyer ağaç içerisindeki skolekslere bağlı olarak gelişen kolanjit karaciğer KE'sinin sık görülen bir komplikasyonudur (8-11). Belli ve arkadaşları (12) intrabiliyer rüptüre bağlı rekürren kolanjit oranını \% 21 olarak bildirmişlerdir.

Karaciğer KE'sinin komplikasyonları; kalsifikasyon, kist kavitesinde enfeksiyon, intrabiliyer rüptür, kolanjit, sarılık ve akut pankreatitdir.

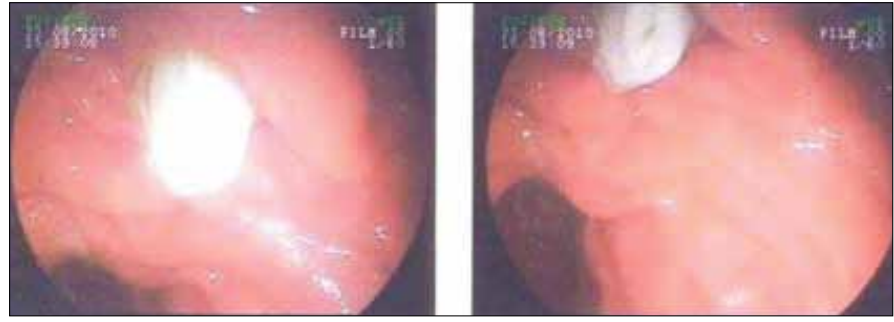

Resim 1. ERCP'de ampulla waterii ağzına oturmuş kist hidatik membranı

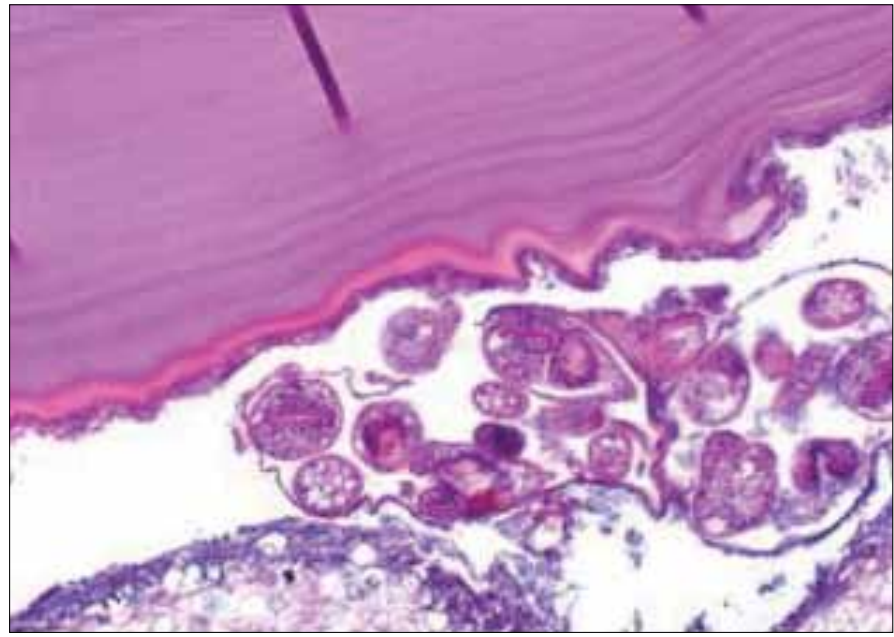

Resim 2. Histopatolojik olarak kist hidatik membranı ve skoleksler (Hemotoksilen eozin $\times 100$ )

Bizim hastamızda hepatik KE ile ilişkili geniş bir komplikasyon spektrumundan nadir görülen akut pankreatit olgusuydu.

Biliyer ağaca rüptürü olan hastalarda kolanjit ve/veya sarılık mevcutsa ERCP tanı ve tedavi için ilk yapılması gereken işlemdir (13).

\section{SONUÇ}

Bizim hastamızda ampulla wateriiye oturmuş kist hidatik membranına bağlı sarılık ve akut pankreatit olduğu için ERCP yapıldı ve işlem sonrası hastanın kliniği dramatik olarak düzeldi. Bu olgu sunumu hepatik KE'nin biliyer rüptürü sonucu olan akut pankreatit vakalarında endoskopik sfinkterotominin ve membranların çıkarılmasının seçilecek prosedür olduğunu göstermektedir. Bu hastalarda nihai ve tamamlayıcı tedavinin cerrahi tedavi olduğu unutulmamalıdır (14).

\section{Çıkar Çatışması}

Yazarlar herhangi bir çıkar çatışması bildirmemişlerdir.

\section{KAYNAKLAR}

1. Milicevic M. Hydatid disease. In: Blumgart LH, Fong $Y$, eds, editors. Surgery of the Liver and Biliary Tract. 3rd ed. London: Churchill Livingstone; 1994. p. 1121-50.

2. Ammann RW, EckertJ. Cesodes. Echinococcus. Gastroenterol Clin North Am 1996; 25: 655-89. [CrossRef]

3. Miguet JP, Bresson-Hadni S, Vuitton D. Echinococcosis of the liver. In: Rodes J, Benhamou JP, Bircher J, Mclntyre N, Rizzetto M, editors. Oxford Textbook of Clinical Hepatology. 2. Vol. 1. Barcelona: Ediciones Cientificas y Tecnicas; 1993. pp. 839-49.

4. Mentes A, Batur Y, Ahmet E. Pancreatitis as a complication of hydatid liver cyst. Jpn J Surg 1990; 20: 356-8. [CrossRef] 
5. Al-Toma AA, Vermeijden RJ, Van De Wiel A. Acute pancreatitis complicating intrabiliary rupture of liver hydatid cyst. Eur J Inter Med 2004; 15: 65-7. [CrossRef]

6. Dew H. Some complications of hydatid disease. Br J Surg 2001; 18 : 289-93.

7. Erzurumlu K, Dervisoglu A, Polat C, Senyurek G, Yetim I, Hokelek M. Intrabiliary rupture: an algorithm in the treatment of controversial complication of hepatic hydatidosis. World J Gastroenterol 2005; 11: 2472-6.

8. Alper A, Arıoğlu O, Emre A. Choledochoduodenostomy for intrabiliary rupture of hydatic cysts. Br J Surg 1987; 74: 243-5. [CrossRef]

9. Moreno VF, Lopez EV. Acute cholangitis caused by ruptured hydatis cyst. Surgery 1985; 97: 249.
10. Ovnat A, Peiser J, Avinoah E, Barki Y, Charuzi I. Acute cholangitis caused by ruptured hydatic cyst. Surgery 1984; 95: 497-500.

11. Vicente VFM, Garcia EM, Marca MAS. Endoscopic retrograde cholangiography and complicated hepatic hydatic cyst in the biliary tract. Endoscopy 1984; 16: 124-6. [CrossRef]

12. Belli $L$, del Favero E, Marni A, Romani F. Resection versus pericystectomy in the treatment of hydatidosis of the liver. Am J Surg 1983; 145: 239-42. [CrossRef]

13. Choliz JD, Olaverri FJL, Zubieta SO. Computed tomography in hepatic echinococosis. AJR 1982; 139: 699-702.

14. Ghidirim G, Mişin I, Gutu E, Gagauz I, Danci A, Vozian M, et al. [Intrabiliary rupture of the hydatic cyst complicated with acute pancreatitis]. Chirurgia (Bucur) 2006; 101: 429-32. 